University of Wollongong

Research Online

Faculty of Engineering - Papers (Archive)

Faculty of Engineering and Information

Sciences

December 2006

\title{
Enhanced Criterion for Base Soil Retention in Embankment Dam Filters
}

Buddhima Indraratna

University of Wollongong, indra@uow.edu.au

A. K. Raut

University of Wollongong

Follow this and additional works at: https://ro.uow.edu.au/engpapers

Part of the Engineering Commons

https://ro.uow.edu.au/engpapers/340

\section{Recommended Citation}

Indraratna, Buddhima and Raut, A. K.: Enhanced Criterion for Base Soil Retention in Embankment Dam

Filters 2006.

https://ro.uow.edu.au/engpapers/340

Research Online is the open access institutional repository for the University of Wollongong. For further information contact the UOW Library: research-pubs@uow.edu.au 


\title{
Enhanced Criterion for Base Soil Retention in Embankment Dam Filters
}

\author{
Buddhima Indraratna, F.ASCE ${ }^{1}$; and Ashok K. Raut ${ }^{2}$
}

\begin{abstract}
In effective filters, potentially erodible base particles are transported to the filter and retained to form a stable self-filtration layer. At any given time, the mass proportion of the filter and the base materials in this layer depends on the initial porosity of the filter and the subsequent porosity of the self-filtration layer. In this paper, an analytical procedure is given to obtain the particle size distribution (PSD) of the self-filtration layer by combining the PSDs of the filter and the base soil modified by $D_{c 95}$, where $95 \%$ of filter constrictions are finer than the size denoted by $D_{c 95}$. The assessment of internal stability of the PSD of the self-filtration layer forms a rational model to successfully identify the effective filters from their ineffective counterparts. The proposed model is verified by large-scale laboratory tests carried out by the writers in addition to other published data. The model performance is acceptable in relation to various base and filter materials, and provides an alternative and rigorous design approach by eliminating most limitations of the conventional particle based criteria (e.g., $D_{15} / d_{85}$ ratio).
\end{abstract}

DOI: 10.1061/(ASCE)1090-0241(2006)132:12(1621)

CE Database subject headings: Construction management; Dams, embankment; Filters; Filtration; Soil stabilization.

\section{Introduction}

Design criteria in current engineering practice are mostly based on empirical relationships derived from tests carried out on different combinations of base and filter materials. A typical Terzaghi relationship (USACE 1953) describing effective filters, later extended by Sherard et al. (1984), is as follows:

$$
D_{15} / d_{85} \leqslant 5
$$

where $15 \%$ by mass of filter particles are finer than the size denoted by $D_{15}$, and $85 \%$ by mass of base particles are finer than the size denoted by $d_{85}$. Although the above-mentioned particle-based criterion is valid for uniform base and filter materials, there are a few major limitations associated with this when used with wellgraded materials. First, the existing particle based criteria do not distinguish between uniform and well-graded filters if they have the same $D_{15}$, which invariably makes any design involving wellgraded filters conservative. Consequently the filters may be prone to clogging in the long term. Indraratna et al. (1990) found that if

${ }^{1}$ Professor of Civil Engineering, Univ. of Wollongong, Wollongong City, NSW 2522, Australia (corresponding author). E-mail: indra@ uow.edu.au

${ }^{2} \mathrm{Ph} . \mathrm{D}$. Candidate, Division of Civil Engineering, Univ. of Wollongong, Wollongong City, NSW 2522, Australia. E-mail: akr84@ uow.edu.au

Note. Discussion open until May 1, 2007. Separate discussions must be submitted for individual papers. To extend the closing date by one month, a written request must be filed with the ASCE Managing Editor. The manuscript for this paper was submitted for review and possible publication on September 28, 2005; approved on April 21, 2006. This paper is part of the Journal of Geotechnical and Geoenvironmental Engineering, Vol. 132, No. 12, December 1, 2006. @ASCE, ISSN 10900241/2006/12-1621-1627/\$25.00. the filters are excessively graded, the risk of clogging is introduced. The current design practice (NRCS 1994) exercises some control to keep the filter bandwidth narrow to avoid the selection of gap-graded filters and prevent segregation during installation. Second, they ignore the effect of filter compaction (unit weight) on the constriction size, and third, they do not differentiate between uniform and well-graded base soils if they have the same $d_{85}$. Lafleur (1984) showed that the representative base particle size in the well-graded base soils is significantly finer than $d_{85}$, and therefore, the use of $d_{85}$ sometimes makes the designs unsafe. Based on filter tests involving well-graded (broadly graded) cohensionless soils, Lafleur et al. (1989) suggested the use of $d_{50}-d_{80}$ as a representative range of particle size in well-graded base soils. NRCS (1994) recommends the use of $d_{85}$ after regrading the base soil particle size distribution (PSD) for particles larger than \#4 sieve size $(4.75 \mathrm{~mm})$, i.e., $d_{85 R}$ rather than the conventional $d_{85}$. Foster and Fell (2001) found that the filter effectiveness diminishes with the increase of fines content in the base soils (i.e., the base soils with wider gradation).

An enhanced method for identifying effective filters must address the limitations described earlier. The recent studies by Locke et al. (2001) and Raut and Indraratna (2004) they discuss in detail the limitations of a mass-based approach and a numerical constriction model. They also provide an analytical computation procedure to determine the constriction size distribution (CSD) of a granular filter based on the surface area of particles, the PSD and the anticipated relative density or porosity of the filter material. The theoretical concepts and the formulations of the CSD computational procedure are given in the Appendix. This paper provides a rigorous analytical model to demarcate between effective and ineffective filters using the constriction size concept, which captures the fundamental mechanisms of filtration. The writers have verified the model using their own laboratory results and experimental data available in the literature. 


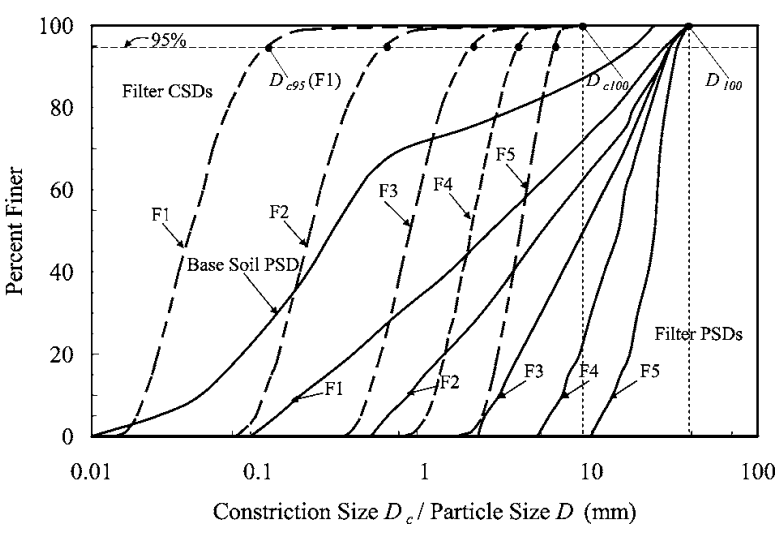

Fig. 1. Dominant constrictions in various types of filters

\section{Formation of Self-Filtration Layer}

\section{PSD of Self-Filtration Layer}

Potentially erodible base particles are transported to the filter by hydrodynamic forces. As suggested by Kenney et al. (1985), base particles larger than controlling constriction size are initially captured by constrictions, resulting in finer constrictions, which then progressively retain smaller base particles. In this manner, a selffiltration layer is formed immediately downstream from the base soil-filter interface. Fig. 1 presents five filters, F1-F5, used by Lafleur (1984), where CSDs are computed for a relative density of $70 \%$ based on the method described by Locke et al. (2001). As the size of the largest particles $D_{100}$ in all filters is the same, the size of the largest constriction $D_{c 100}$ is also expected to be the same. However, in well-graded filters, the sizes of dominant constrictions should be considerably smaller than $D_{c 100}$. For instance, Fig. 1 shows that $D_{c 95}$ is more appropriate for distinguishing between Filters F1 and F5 at the upper end of the coarse constrictions. The choice of $D_{c 95}$ is further justified by Locke et al. (2001) based on a set of well-defined probability equations. Accordingly there is a $95 \%$ chance that a base particle larger than $D_{c 95}$ cannot penetrate a single layer of the filter and therefore would not influence self-filtration. This modification of the base soil PSD also explains why the coarser particle fraction could be ignored in filter designs that involve well-graded and internally unstable gap-graded base soils (Lafleur et al. 1989). In other words it can be concluded that the PSD of the self-filtration layer is formed by filter particles and the base particles finer than the constriction size $D_{c 95}$. Now the question arises, what will be the relative mass proportions of the filter and base particles in the self-filtration layer?

Kenney and Lau (1985) mentioned that the captured base particles usually remain in a loose state within the filter pores, resulting in a net porosity $\left(n_{B}\right)$ of about 0.40 . The initial filter porosity $\left(n_{F}\right)$ depends on the field compaction. Assuming that the specific gravity of the base and filter particles is the same and considering a unit volume of self-filtration layer

Volume of filter particles, $V_{S F}=1-n_{F}$

Volume of base particles, $V_{S B}=\left(1-n_{B}\right) n_{F}$

Fraction of filter particles in self-filtration layer,

$$
P_{F}=V_{S F} /\left(V_{S F}+V_{S B}\right)=\left(1-n_{F}\right) /\left(1-n_{F} n_{B}\right)
$$

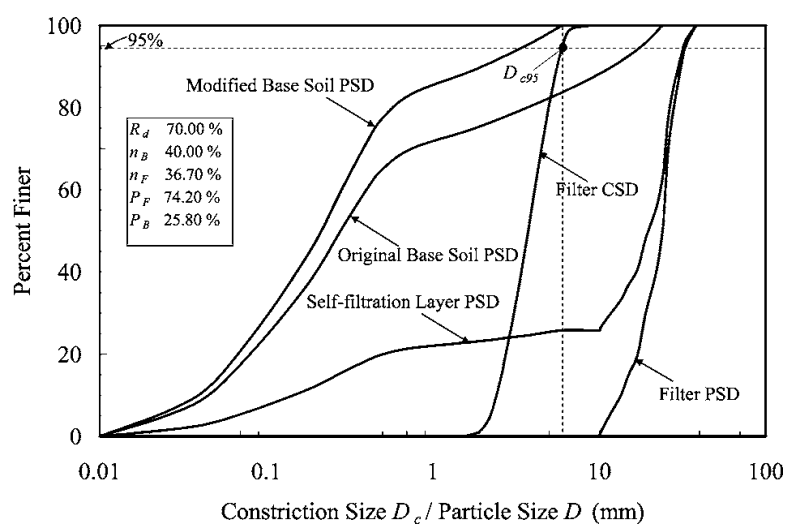

Fig. 2. PSD of self-filtration layer in a typical base soil-filter combination

Fraction of base particles in self-filtration layer,

$$
\begin{gathered}
P_{B}=V_{S B} /\left(V_{S F}+V_{S B}\right)=\left[\left(1-n_{B}\right) n_{F}\right] /\left(1-n_{F} n_{B}\right) \\
P_{F} / P_{B} \text { ratio }=\left(1 / n_{F}-1\right) /\left(1-n_{B}\right)
\end{gathered}
$$

Once the mass proportions are determined, employing the $P_{F} / P_{B}$ ratio, the PSD of self-filtration layer can be obtained by combining the PSD of the base soil (modified by disregarding any base particles larger than $D_{c 95}$ ) and the PSD of the filter.

In order to illustrate the computation procedure for determining the PSD of the self-filtration layer, the particle size and constriction size distributions of the Filter F5 and the base soil from Fig. 1 are replotted in Fig. 2. The CSD is computed following the method of Locke et al. (2001) and $D_{c 95}$ is $6 \mathrm{~mm}$. The modified PSD of the base soil is then calculated by ignoring all base particles larger than $6 \mathrm{~mm}$, which is presented in Fig. 2. Knowing the relative density $\left(R_{d}=70 \%\right)$, the equivalent porosity $n_{F}$ is calculated to be about $36 \%$. As mentioned earlier a value of $40 \%$ is considered for $n_{B}$. Subsequently $P_{F}$ and $P_{B}$ are calculated as described earlier and found to be 74.20 and $25.80 \%$, respectively. Finally the PSD of the self-filtration layer (Fig. 2) is obtained by combining the filter PSD and the modified base soil PSD in the ratio of $P_{F}: P_{B}$ (approximately $3: 1$ ).

\section{Internal Stability of Self-Filtration Layer}

In order to illustrate the base soil and filter interaction in the self-filtration layer, the PSDs of the self-filtration layers corresponding to Filters F1-F5 (Fig. 1) are determined and plotted in Fig. 3. The progressively widening "gaps" in the PSD curves of self-filtration layers corresponding to the coarser filters (F3, F4, and F5) imply their internally unstable, gap-graded nature. These coarser filters may not be able to retain the potentially erodible fine base particles, which will probably render them ineffective. By contrast, the self-filtration layers of the finer filters (F1 and F2) do not have "gaps," hence, they represent internally stable soils. These filters are most likely to retain the potentially erodible base particles, thereby considered to be effective. The internal stability of a self-filtration layer can be examined using the Kenney and Lau (1985) method succinctly presented in Fig. 4. An evaluation of the internal stability of filters based on self-filtration leads to a rigorous model for identifying effective filters. The proposed approach of using the largest dominant constriction size $D_{c 95}$ for disregarding coarser particles, which do not influence filtration is more comprehensive than the Terzaghi method of 


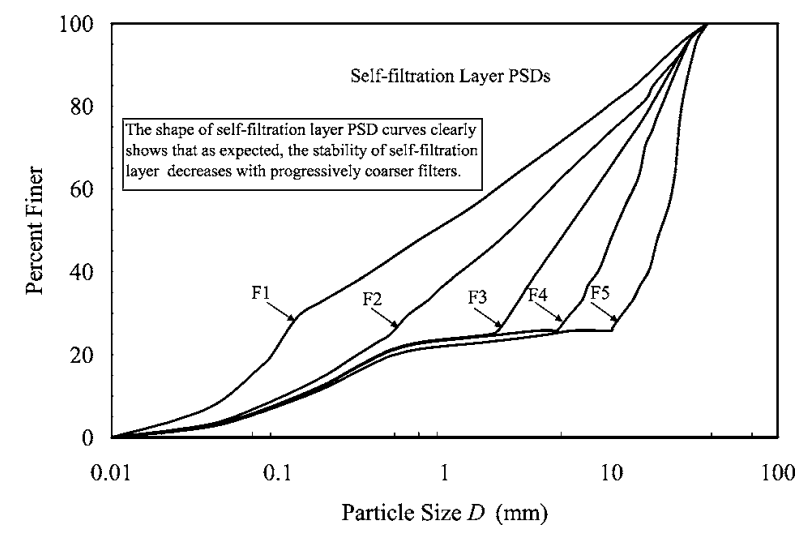

Fig. 3. PSDs of self-filtration layers in progressively coarser filters

using particle size ratios, especially with well-graded soils. In this respect, the aim of the proposed model is to use the derived PSD curve for the self-filtration layer to determine the $\mathrm{H} / \mathrm{F}$ ratio, in order to examine the stability of a given base soil-filter system.

\section{Model Verification}

Data from several filter tests carried out by the writers and by others were analyzed using the current model. A few examples of which are considered here as illustrations. Indraratna and Vafai (1997) carried out two large-scale tests using Wollongong beach sand as the base soil and subrounded river pebbles as the filter material. Both base and filter materials are uniform with $C_{u}$ just below 3 . The filters were compacted to a relative density of $90 \%$, i.e., an equivalent porosity $n_{F}$ of about $31 \%$. The retention ratios $D_{15} / d_{85}$ in these tests F1 and F2 are 1.78 and 9.94, respectively. The laboratory observations indicated that Filter F1 was effective and F2 ineffective. The values of $P_{F}$ and $P_{B}$ were determined to be 78.37 and $21.63 \%$, respectively. The filter CSDs were calculated and the corresponding constriction sizes $D_{c 95}$ are 0.32 and $1.71 \mathrm{~mm}$ for F1 and F2, respectively. The modified PSD of the base soil and the PSDs of the self-filtration layers for these two filters are presented in Figs. 5( $\mathrm{a}$ and $\mathrm{b}$ ). The internal stability of the layers was subsequently checked by calculating the $\mathbf{H} / \mathbf{F}$ ratios in the range of $\mathbf{F}=0-30 \%$. This relatively larger range of $\mathbf{F}=0-30 \%$ was considered because the coarser part of the PSD of the self-filtration layer is predominantly composed of uniform filter grains $\left(C_{u}=2.87\right)$. The analysis shows that for $\mathrm{F} 1$, the minimum $\mathbf{H} / \mathbf{F}$ ratio is 1.40 at $\mathbf{F}=9.01$ with corresponding $\mathbf{H}=12.59$. For $\mathrm{F} 2$, the minimum $\mathbf{H} / \mathbf{F}$ ratio is 0.017 at $\mathbf{F}=21.63$ and $\mathbf{H}=0.37$. For $\mathrm{F} 1, \mathbf{H} / \mathbf{F}>1$ in the range of $\mathbf{F}=0-30 \%$ indicates

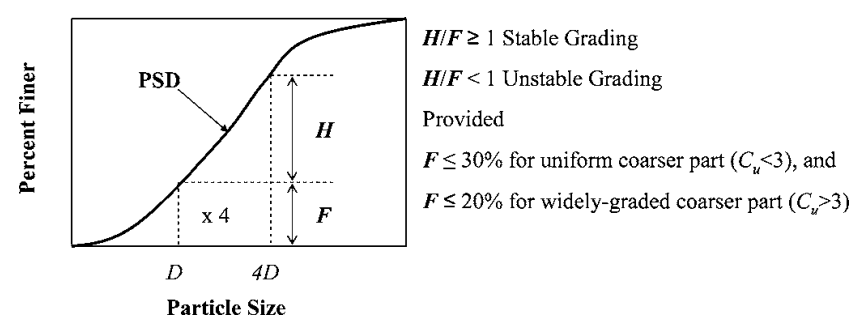

Fig. 4. Graphical representation of the procedure from Kenney and Lau (1985) for internal stability assessment

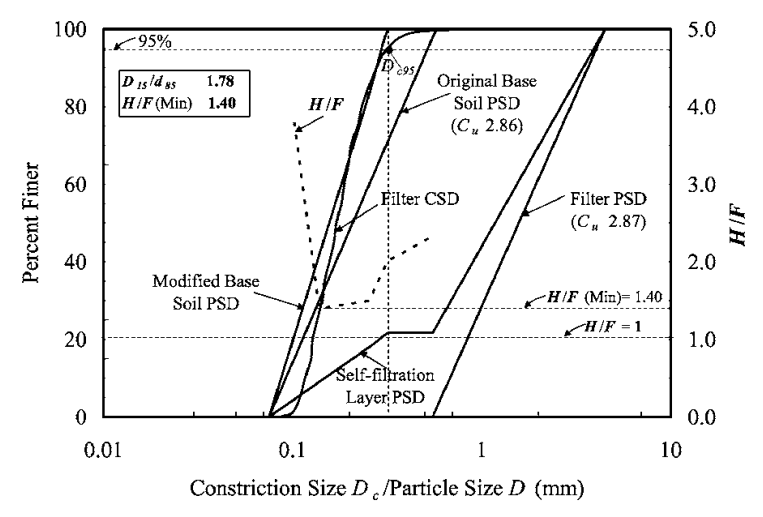

(a)

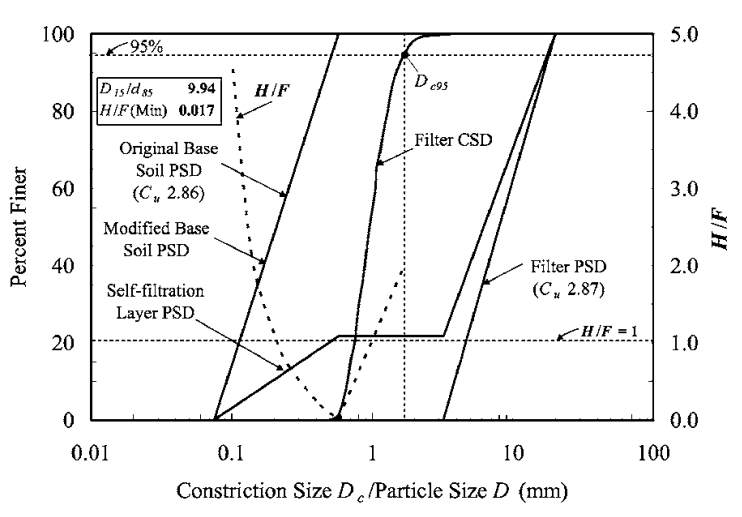

(b)

Fig. 5. Analyses of (a) effective uniform Filter F1 with a uniform base soil; (b) ineffective uniform Filter F2 with a uniform base soil

that the PSD of self-filtration layer is internally stable, resulting in an effective filter. For $\mathrm{F} 2, \mathbf{H} / \mathbf{F}<1$ in the range $\mathbf{F}=0-30 \%$, which suggests that a stable self-filtration layer could not be formed, resulting in an ineffective filter. Thus the model predictions confirm the laboratory observations.

The writers also conducted several filter tests using wellgraded base soils tested against uniform and well-graded filters. The well-graded base soil $\left(C_{u}=9.33\right)$ was prepared by mixing clean quarry sands of different uniform sizes with a non-plastic sandy silt soil at 50:50 proportions. Similarly the well-graded filter was prepared by mixing clean quarry sands of different uniform sizes with river pebbles of various uniform sizes. The porosity of filters was determined in relation to a compacted relative density of $70 \%$, i.e., equivalent porosity $n_{F}$ of $36 \%$. For this wellgraded base soil $\left(C_{u}=9.33\right)$, the PSD and CSD analysis is illustrated for F1 and F2 filters in Figs. 6(a and b), respectively. $C_{u}$ for Filters F1 and F2 are 1.20 and 5.23, respectively. The corresponding retention ratios $D_{15} / d_{85}$ in these tests are 3.57 and 0.18 , respectively. The values of $P_{F}$ and $P_{B}$ were calculated to be 74.18 and $25.82 \%$, respectively. The filter CSDs were determined and the constriction sizes $D_{c 95}$ were calculated to be 1.46 and $0.16 \mathrm{~mm}$ for F1 and F2, respectively. The modified PSDs of the base soil and the PSD of the self-filtration layers of these filters are also presented in Figs. 6( $\mathrm{a}$ and $\mathrm{b}$ ). The internal stability of the layers was examined by calculating $\mathbf{H} / \mathbf{F}$ ratios in the range of $\mathbf{F}=0-30 \%$ for $\mathrm{F} 1$ and in the range of $\mathbf{F}=0-20 \%$ for $\mathrm{F} 2$. A smaller range $\mathbf{F}=0-20 \%$ was considered for $\mathrm{F} 2$ because the coarser part of the PSD of the self-filtration layer is predominantly well-graded $\left(C_{u}>3\right)$. The analysis shows that for F1, the 


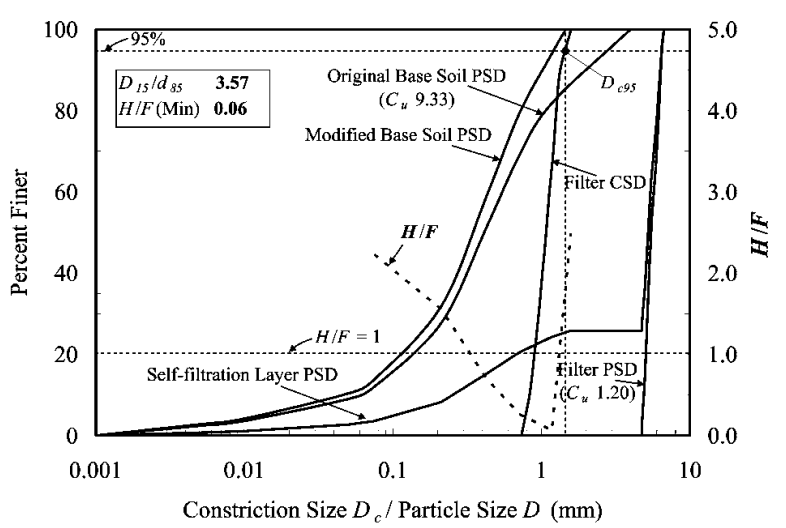

(a)

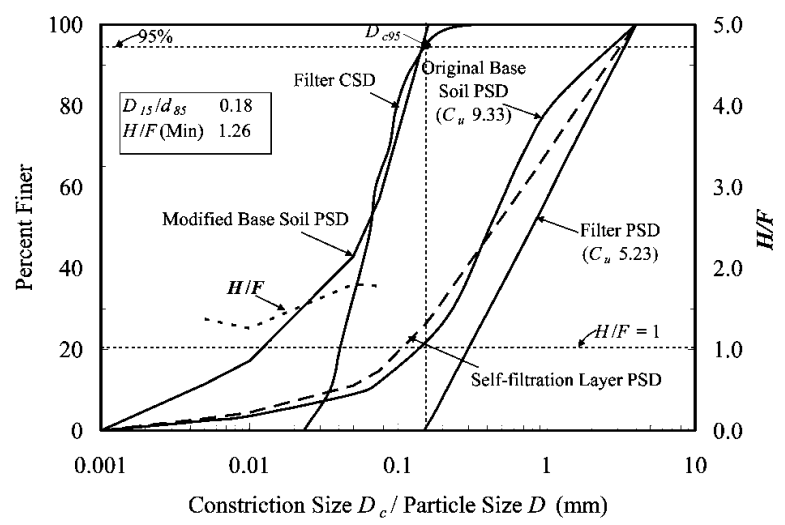

(b)

Fig. 6. Analyses of (a) an ineffective uniform Filter F1 with a well-graded base soil; (b) an effective well-graded Filter F2 with a well-graded base soil

minimum $\mathbf{H} / \mathbf{F}$ ratio is 0.06 at $\mathbf{F}=24.27$ with corresponding $\mathbf{H}=1.55$, and for $\mathbf{F} 2$, the minimum $\mathbf{H} / \mathbf{F}$ ratio is 1.26 at $\mathbf{F}=4.43$ and $\mathbf{H}=5.57$, confirming the laboratory observations that Filter F1 was ineffective and F2 effective. The previous examples verify that the writers' approach can successfully distinguish between effective and ineffective filters.

\section{Comparison with Existing Criteria}

\section{Terzaghi Method}

Twenty-seven sets of test data were analyzed using the current approach and Terzaghi retention criterion. The results are tabulated in Table 1 and also presented in Figs. 7 and 8. Data were taken mostly from the tests involving well-graded base soils, where most conventional particle based criteria exhibit limitations. For example, Fig. 7 clearly shows that some filters involving retention ratios $D_{15} / d_{85}$ well below $4-5$ failed to retain the well-graded base soils but still plot in the effective zone. Fig. 8, however, based on the writers' current approach, clearly illustrates that none of the failed tests plot on the effective zone $(\mathbf{H} / \mathbf{F}>1)$ established by the model. It is to be noted that in order to enhance clarity of a large number of data points, Fig. 8 has been divided into four parts [Figs. 8(a-d)]. A few data points showing limited erosion, i.e., \#7 [Indraratna et al. 1996; Fig. 8(a)], \#12 [Lafleur 1984; Fig. 8(b)], and \#14 and \#19
[Fig. 8(c)] cross the $\mathbf{H} / \mathbf{F}=1$ boundary to the ineffective zone, albeit considered effective in laboratory tests. As mentioned by Indraratna and Vafai (1997) and Lafleur (1984), these tests take a much longer time to establish self-filtration compared to the effective filters, and are normally associated with a significant initial loss of the base soil through the filter. In this regard, both \#7 and \#12 should be categorized as initially ineffective. Data points \#14 and \#19 represent the writers' recent tests involving uniform base soils. Similar to the observations discussed earlier, these tests also showed limited erosion and relatively longer selffiltration time before the filters attended some stability. In Fig. 7, the writers have used different symbols for these points to indicate "limited erosion."

\section{Current Design Implications}

Regrading of base soil (NRCS 1994) and the proposed $D_{c 95}$ criterion based on self-filtration and internal stability are two alternatives to address the same limitations of the original Terzaghi filtration approach. The current model cannot be directly compared with the NRCS (1994) guidelines where the filter boundaries vary depending on the percentage of fines in the base soils. However, as Kenney and Lau (1985) internal stability method is based on cohensionless soils, the current model can be compared to the regraded criterion $\left(D_{15} / d_{85 R} \leqslant 4\right)$ for cohensionless base soils (Fig. 9). Fig. 9 represents $d_{85 R}$ on the horizontal axis, and the boundary $D_{15} / d_{85 R}=4$ demarcates the effective filters from the ineffective ones. It can be seen that although the regraded boundary applies well for cohensionless soils, the proposed $D_{c 95}$ model employing $\mathbf{H} / \mathbf{F}$ technique is equally acceptable (Fig. 8).

The key advantage of the writers' proposed approach based on $D_{c 95}$ is that regrading of base soil is not required. Also, as the $\mathbf{H} / \mathbf{F}$ ratio of the proposed method inherently includes internal stability, the designer is not required to carry out a prior analysis to examine the internal stability of the base soil. Moreover, plotting the self-filtration PSDs (Fig. 3) where a "gap" is evident in all ineffective base soil-filter combinations will certainly boost the designer's confidence. In this respect, the proposed model is essentially more comprehensive because it takes of filter compaction, porosity and coefficient of uniformity $\left(C_{u}\right)$ into account and considers self-filtration and internal stability to enhance the rigor in assessing filter effectiveness.

\section{Conclusions}

When eroded base particles are transported to the filter, only coarser particles larger than the controlling constriction size are initially captured. These finer constrictions progressively retain finer base particles to form a self-filtration layer. Base particles larger than the constriction size $D_{c 95}$ do not influence the process of self-filtration because they do not penetrate the filter. Therefore, the constriction size $D_{c 95}$ is a reasonable cutoff value, and the base soil PSD modified accordingly is more realistic in the analysis of filtration.

Mass retained in the self-filtration layer depends on the initial porosity of the filter and the subsequent porosity of the selffiltration layer. The PSD of the self-filtration layer can be determined by combining the initial filter PSD and the modified base soil PSD incorporating $D_{c 95}$. In effective filters potentially erodible base particles must form an internally stable self-filtration layer that is not gap-graded or concave upward. An assessment of the internal stability of the layer on the basis of $\mathbf{H} / \mathbf{F}$ ratios gives 
Table 1. Analysis of Test Results Using the Current Model and Existing Criteria

\begin{tabular}{|c|c|c|c|c|c|c|c|c|c|c|c|c|}
\hline \multirow{2}{*}{$\begin{array}{l}\text { Test } \\
\text { number }\end{array}$} & \multicolumn{3}{|c|}{ Base soil } & \multicolumn{3}{|c|}{ Filter } & \multirow{2}{*}{$\begin{array}{l}D_{15} / d_{85} \\
(\mathrm{~mm})\end{array}$} & \multirow{2}{*}{$\begin{array}{l}F^{\mathrm{a}} \\
(\%)\end{array}$} & \multirow{2}{*}{$\begin{array}{l}H^{\mathrm{a}} \\
(\%)\end{array}$} & \multirow[b]{2}{*}{$H / F$} & \multirow{2}{*}{$\begin{array}{l}\text { Laboratory } \\
\text { observation }\end{array}$} & \multirow[b]{2}{*}{ Source } \\
\hline & Notation & $C_{u}$ & $d_{85}$ & Notation & $C_{u}$ & $D_{15}$ & & & & & & \\
\hline 1 & Base soil & 2.86 & 0.42 & F1 & 2.87 & 0.75 & 1.78 & 9.00 & 12.50 & 1.40 & Effective & Indraratna and Vafai (1997) \\
\hline 2 & & & & $\mathrm{~F} 2$ & 2.87 & 4.21 & 9.94 & 21.63 & 0.37 & 0.017 & Ineffective & \\
\hline 3 & Base soil & 11.40 & 1.18 & F-1-40 & 1.30 & 5.10 & 4.32 & 24.53 & 1.46 & 0.059 & Ineffective & Current study \\
\hline 4 & Base soil & 9.33 & 1.40 & $\mathrm{~F} 1$ & 1.20 & 5.00 & 3.57 & 20.75 & 4.72 & 0.060 & Ineffective & \\
\hline 5 & & & & $\mathrm{~F} 2$ & 5.23 & 1.40 & 0.18 & 4.43 & 5.57 & 1.26 & Effective & \\
\hline 6 & Base soil & 1.29 & 0.04 & Coarse & 1.47 & 0.68 & 15.45 & 29.58 & 0.02 & 0.001 & Ineffective & Indraratna et al. (1996) \\
\hline 7 & & & & Medium & 1.45 & 0.23 & 5.18 & 26.19 & 3.41 & 0.13 & Effective & \\
\hline 8 & & & & Fine & 1.28 & 0.12 & 2.72 & 20.40 & 24.60 & 1.21 & Effective & \\
\hline 9 & B-3 & 8.89 & 7.00 & F1 & 25.0 & 0.26 & 0.04 & 19.43 & 20.00 & 1.03 & Effective & Lafleur (1984) \\
\hline 10 & & & & $\mathrm{~F} 2$ & 8.00 & 1.00 & 0.14 & 20.00 & 20.00 & 1.00 & Effective & \\
\hline 11 & & & & F3 & 4.29 & 3.20 & 0.46 & 20.00 & 4.50 & 0.23 & Ineffective & \\
\hline 12 & & & & F4 & 2.39 & 7.30 & 1.04 & 22.87 & 2.63 & 0.12 & Effective & \\
\hline 13 & & & & F5 & 1.85 & 15.00 & 2.14 & 21.51 & 2.49 & 0.12 & Ineffective & \\
\hline 14 & Base soil & 1.2 & 0.4 & $\mathrm{~F} 1$ & 1.44 & 2.50 & 6.25 & 18.39 & 3.20 & 0.17 & Effective & Current study \\
\hline 15 & & & & $\mathrm{~F} 2$ & 1.18 & 1.30 & 3.25 & 21.63 & 24.00 & 1.11 & Effective & \\
\hline 16 & Base soil & 1.18 & 0.28 & F3 & 1.17 & 3.60 & 12.86 & 20.00 & 1.60 & 0.08 & Ineffective & \\
\hline 17 & Base soil & 1.28 & 0.116 & F4 & 1.28 & 0.47 & 4.00 & 15.49 & 15.51 & 1.00 & Effective & \\
\hline 18 & & & & F5 & 1.28 & 0.58 & 5.00 & 20.00 & 6.00 & 0.30 & Effective & \\
\hline 19 & & & & F6 & 1.28 & 0.69 & 6.00 & 23.23 & 2.77 & 0.12 & Effective & \\
\hline 20 & B1 & 2.63 & 1.55 & $\mathrm{~F} 1$ & 1.2 & 7.3 & 4.71 & 22.8 & 1.5 & 0.116 & Ineffective & \\
\hline 21 & & & & $\mathrm{~F} 2$ & 3.12 & 1.40 & 0.90 & 20.00 & 25.00 & 1.25 & Effective & \\
\hline 22 & B2 & 5.2 & 1.28 & $\mathrm{~F} 1$ & 1.20 & 7.30 & 5.70 & 22.00 & 2.60 & 0.11 & Ineffective & \\
\hline 23 & & & & $\mathrm{~F} 2$ & 4.47 & 0.78 & 0.61 & 19.00 & 24.00 & 1.26 & Effective & \\
\hline 24 & B3 & 5.85 & 0.75 & $\mathrm{~F} 1$ & 1.20 & 7.30 & 9.73 & 25.00 & 1.50 & 0.06 & Ineffective & \\
\hline 25 & & & & $\mathrm{~F} 2$ & 3.12 & 1.40 & 1.87 & 15.00 & 15.49 & 1.03 & Effective & \\
\hline 26 & B4 & 8.75 & 1.8 & $\mathrm{~F} 1$ & 1.20 & 7.30 & 4.06 & 28.00 & 1.46 & 0.05 & Ineffective & \\
\hline 27 & & & & $\mathrm{~F} 2$ & 3.12 & 1.40 & 0.78 & 12.69 & 13.30 & 1.05 & Effective & \\
\hline
\end{tabular}

${ }^{\mathrm{a}}$ Values where $H / F$ is minimum in the range of $0-20 \%$ or $0-30 \%$, whichever is applicable.

rise to a rigorous analytical model to successfully identify effective filters. Considering the test data discussed in this study, the prediction of filter effectiveness based on the writers' approach is accurate in relation to various combinations of base and filter materials for uniform and well-graded base soils. The current model provides a more rational and rigorous procedure for filter design by eliminating the obvious limitations of conventional particle size criteria based on the $D_{15} / d_{85}$ ratio alone.

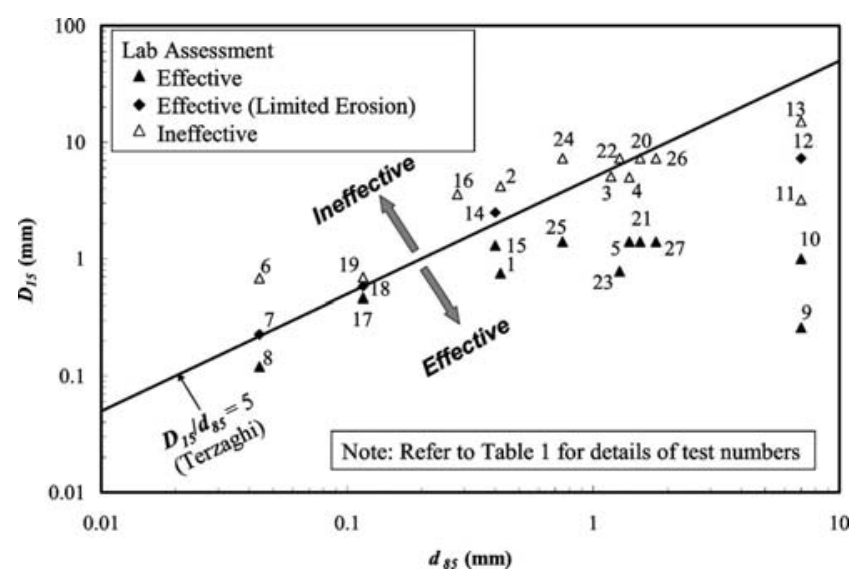

Fig. 7. Comparative analysis of test results using the original Terzaghi retention criterion (i.e., before regrading of the base soil)

\section{Acknowledgments}

The writers express their special thanks to Dr. Mark Locke (SMEC-International), former Ph.D. candidate at the University of Wollongong, for his contribution to the development of initial framework of the CSD model. The support provided by Snowy Mountain Engineering Corporation (SMEC, Melbourne) and Sinclair Knight Mertz Ltd. (SKM, Sydney) in this area of research is appreciated.

\section{Appendix. Theoretical Concepts of Filter CSD Computation Procedure}

The main theoretical concepts describing the nature of constriction size distribution (CSD) of a filter have been addressed by Indraratna and Locke (2000), Raut and Indraratna (2004), and Locke et al. (2001). In this study, the writers have extended the above principles and have developed a computational procedure to determine the filter constriction size distribution (CSD) for a given particle size distribution (PSD) and relative density $\left(R_{d}\right)$. Some salient features of the constriction model are elucidated below.

\section{Constriction Sizes in the Most Dense and Most Loose Particle Arrangements}

In a real granular filter, particles exist in a group of three or four, representing the most dense and the most loose arrangements, 

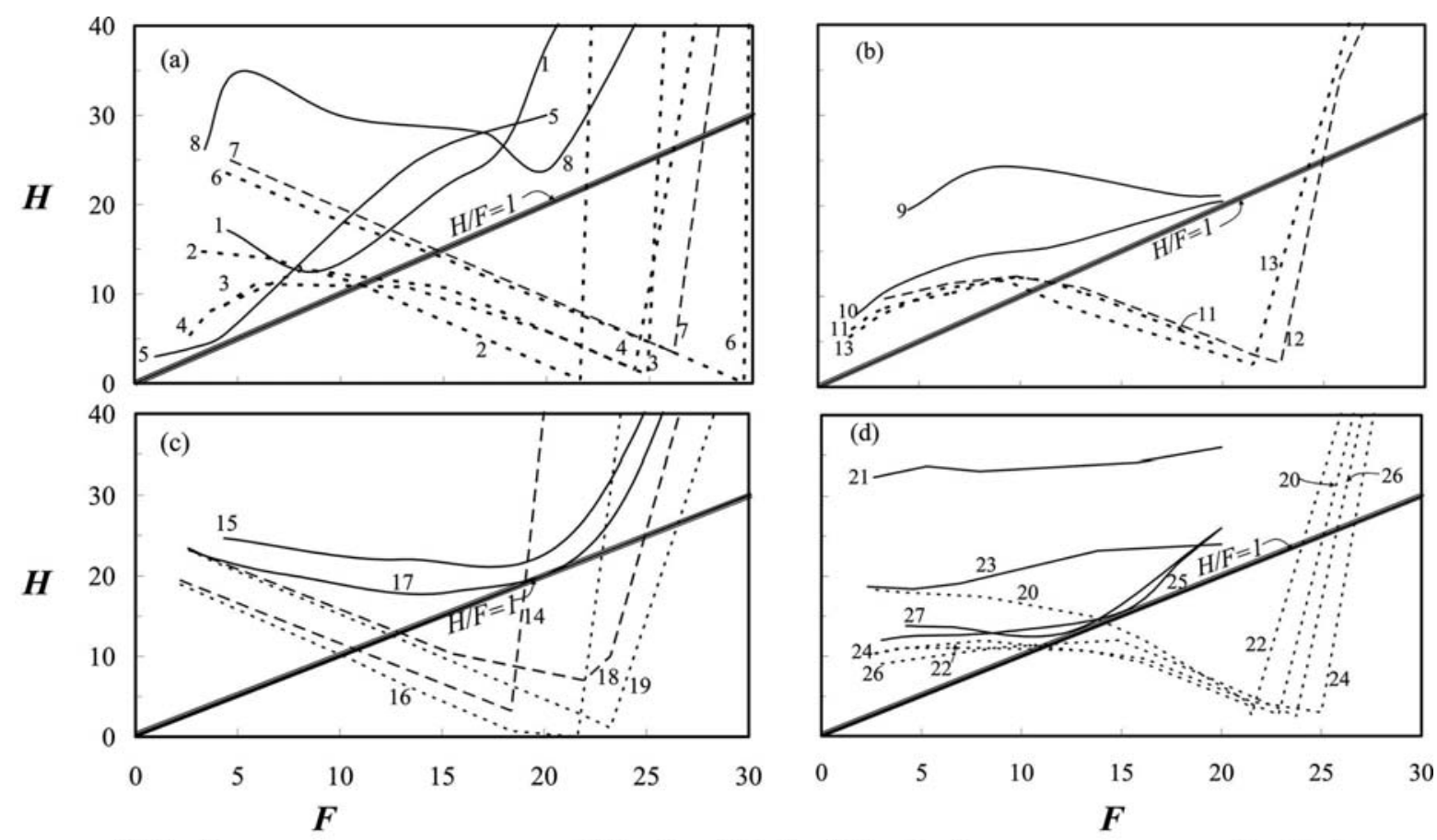

Effective

\section{Effective (Limited Erosion)}

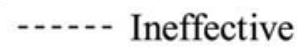

Fig. 8. Comparative analysis of test results using the current model (a) Tests 1-8; (b) Tests 9-13; (c) Tests 14-19; and (d) Tests 20-27 (refer to Table 1 for details of test numbers)

respectively. Humes (1996) assumed that in a filter at maximum density, only the most dense arrangements exist, and defined the constriction size $D_{c D}$ as the diameter of the largest circle that can fit within three tangent filter particles, which can be given by

$$
\begin{aligned}
& \left(\frac{2}{D_{1}}\right)^{2}+\left(\frac{2}{D_{2}}\right)^{2}+\left(\frac{2}{D_{3}}\right)^{2}+\left(\frac{2}{D_{c D}}\right)^{2}=0.5\left[\left(\frac{2}{D_{1}}\right)+\left(\frac{2}{D_{2}}\right)+\left(\frac{2}{D_{3}}\right)\right. \\
& \left.+\left(\frac{2}{D_{c D}}\right)\right]^{2}
\end{aligned}
$$

However, a real filter is not always compacted to its maximum density, which implies that the densest constriction model is conservative. For any general particle arrangement, the constriction

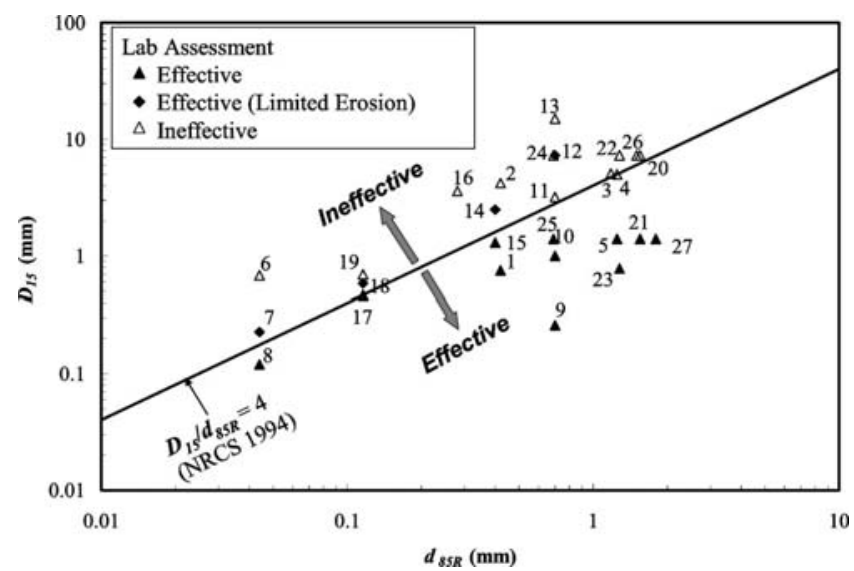

Fig. 9. Application of retention criteria to distinguish between effective and ineffective filters using the current design practice with regraded base soil PSDs (data adapted from NRCS 1994) space $S_{c}$ between four particles is then given by (Silveira et al. 1975)

$$
\begin{aligned}
S_{c}= & \frac{1}{8}\left[\left(D_{1}+D_{2}\right)\left(D_{1}+D_{4}\right) \sin \alpha+\left(D_{2}+D_{3}\right)\left(D_{2}+D_{4}\right) \sin \gamma\right. \\
& \left.-\left(\alpha D_{1}^{2}+\beta D_{2}^{2}+\gamma D_{3}^{2}+\delta D_{4}^{2}\right)\right]
\end{aligned}
$$

where the angles $\beta, \gamma$, and $\delta$ can be related to $\alpha$ by plane geometry. For a particular value of $\alpha$, when the value of $S_{c}$ is maximum, then the corresponding constriction size in the most loose arrangement based on equivalent diameter $D_{c L}$ is given by

$$
D_{c L}=\sqrt{\frac{4 S_{c, \max }}{\pi}}
$$

The probability (frequency) of occurrence of $D_{c D}$ and $D_{c L}$ depends upon the probabilities of individual particles constituting the arrangements, and can be calculated statistically (Silveira et al. 1975). If a filter PSD is divided into a number of particle sizes, in the manner explained previously, $D_{c D}$ and $D_{c L}$, and their corresponding probabilities can be determined for all possible unique combinations of particles in the most dense and most loose states, resulting in the most dense and most loose CSD models.

\section{Particle Frequency and Filter Compaction}

Most researchers have used the densest CSD for simplicity, where the filter PSDs either by mass or by number of particles have been used. However, as explained by Locke et al. (2001), although PSD by mass obtained through sieve analysis is accepted as a good representation of CSD for uniform filters, the use of PSD by mass introduces errors in well-graded filters. This is because large particles with a high individual mass but low in number will be overrepresented, as it is unlikely that these few large particles will meet together to form a large constriction. In a similar manner, 
the PSD by number overrepresents the finer constrictions. Humes (1996) suggested that although there are only a small number of large particles, they impose significant contact with other particles due to their larger surface area, and showed that the filter PSD based on surface area is the best option for filtration analysis.

If a filter material is composed of $\mathrm{n}$ diameters, $D_{1}, D_{2}$, $D_{3}, \ldots, D_{\mathrm{n}}$ and their mass frequencies are $p_{\mathrm{m} 1}, p_{\mathrm{m} 2}$, $p_{\mathrm{m} 3}, \ldots, p_{\mathrm{mn}}$, respectively, then their respective frequencies by surface area $\left(p_{S A i}\right)$ can be obtained by (Humes 1996)

$$
p_{S A i}=\left(\frac{p_{m i}}{D_{i}}\right) /\left(\sum_{i=1}^{n} \frac{p_{m i}}{D}\right)
$$

Similarly, their frequencies by number $\left(p_{N i}\right)$ can be obtained by (Raut and Indraratna 2004)

$$
p_{N i}=\left(\frac{p_{m i}}{D_{i}^{3}}\right) /\left(\sum_{i=1}^{n} \frac{p_{m i}}{D_{i}^{3}}\right)
$$

Real filters are likely to exist in between the two extreme states, most dense and most loose. Irrespective of whether the CSD is determined by mass, number or surface area, the actual constriction size $D_{c}$ for any given relative density $R_{d}$ is given by Locke et al. (2001)

$$
D_{c}=D_{c D}+P_{c}\left(1-R_{d}\right)\left(D_{c L}-D_{c D}\right)
$$

where $D_{c}=$ actual constriction size for a given value of the percent finer $P_{c} ; D_{c D}$ and $D_{c L}=$ constriction sizes in the most dense and most loose models, respectively, for the same $P_{c}$. The writers have incorporated these theoretical concepts in a comprehensive computer program to compute the filter CSD.

\section{References}

Foster, M., and Fell, R. (2001). "Assessing embankment dam filters that do not satisfy design criteria." J. Geotech. Geoenviron. Eng., 127(5), 398-407.

Humes, C. (1996). "A new approach to compute the void-size distribution curves of protective filters." Proc., GeoFilters '96, J. Lafleur and
A. L. Rollin, eds., Bitech Pub., Montreal, 57-66.

Indraratna, B., Dilema, E., and Nutalaya, P. (1990). "Design of granular filters for a lateritic residual soil.” Dam Engineering, 1(3), 201-220.

Indraratna, B., and Locke, M. (2000). "Analytical modeling and experimental verification of granular filter behaviour." Keynote paper, filters and drainage in geotechnical and geoenvironmental engineering, W. Wolski and J. Mlynarek eds., Balkema, Rotterdam, The Netherlands, 3-26.

Indraratna, B., and Vafai, F. (1997). “Analytical model for particle migration within base soil-filter system." J. Geotech. Geoenviron. Eng., 123(2), 100-109.

Indraratna, B., Vafai, F., and Dilema, E. (1996). “An experimental study of the filtration of a lateritic clay slurry by sand filters." Proc. Instn Civ. Engrs. Geotechnical Engineering, 119(2), 75-83.

Kenney, T., Chahal, R., Chiu, E., Ofoegbu, G., Omange, G., and Ume, C. (1985). "Controlling constriction sizes of granular filters." Can. Geotech. J., 22(1), 32-43.

Kenney, T., and Lau, D. (1985). "Internal stability of granular filters." Can. Geotech. J., 22(2), 215-225.

Lafleur, J. (1984). "Filter testing of broadly graded cohesionless tills." Can. Geotech. J., 21(4), 634-643.

Lafleur, J., Mlynarek, J., and Rollin, A. L. (1989). "Filtration of broadly graded cohesionless soils.” J. Geotech. Engrg., 115(12), 1747-1767.

Locke, M., Indraratna, B., and Adikari, G. (2001). "Time-dependent particle transport through granular filters." J. Geotech. Geoenviron. Eng., 127(6), 521-529.

Natural Resources Conservation Services (NRCS). (1994). "Gradation design of sand and gravel filters." Part 633 national engineering handbook, Chap. 26, U.S. Dept. of Agriculture, Washington, D.C.

Raut, A. K., and Indraratna, B. (2004). "Constriction size distribution of a non-uniform granular filter.” Proc., 15th South East Asian Geotechnical Conf., Bangkok, Thailand, 409-414.

Sherard, J., Dunnigan, L., and Talbot, J. (1984). "Basic properties of sand and gravel filters.” J. Geotech. Engrg., 110(6), 684-700.

Silveira, A., de Lorena Peixoto, T., Nogueira, and J. (1975). "On void size distribution of granular materials." Proc., 5th Pan-American Conf. of Soil Mechanics and Foundations Engineering, 161-176.

Unites States Army Corps of Engineers (USACE). (1953). "Investigation of filter requirements for underdrains." Tech. Memo. No. 3-360, U.S. Waterways Experiment Station, Vicksburg, Miss. 